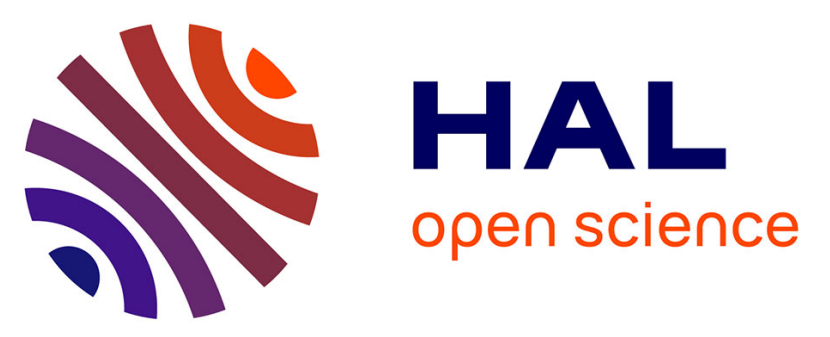

\title{
Thermoelectric performance of codoped (Bi, In)-GeTe and (Ag, In, Sb)-SnTe materials processed by Spark Plasma Sintering
}

Bhuvanesh Srinivasan, Catherine Boussard-Plédel, Bruno Bureau

\section{- To cite this version:}

Bhuvanesh Srinivasan, Catherine Boussard-Plédel, Bruno Bureau. Thermoelectric performance of codoped (Bi, In)-GeTe and (Ag, In, Sb)-SnTe materials processed by Spark Plasma Sintering. Materials Letters, 2018, 230, pp.191-194. 10.1016/j.matlet.2018.07.132 . hal-01874723v2

HAL Id: hal-01874723

https://hal-univ-rennes1.archives-ouvertes.fr/hal-01874723v2

Submitted on 18 Sep 2018

HAL is a multi-disciplinary open access archive for the deposit and dissemination of scientific research documents, whether they are published or not. The documents may come from teaching and research institutions in France or abroad, or from public or private research centers.
L'archive ouverte pluridisciplinaire HAL, est destinée au dépôt et à la diffusion de documents scientifiques de niveau recherche, publiés ou non, émanant des établissements d'enseignement et de recherche français ou étrangers, des laboratoires publics ou privés. 


\title{
Thermoelectric Performance of Codoped (Bi, In)-GeTe and (Ag, In, Sb)-SnTe Materials Processed by Spark Plasma Sintering
}

\author{
Bhuvanesh Srinivasan $^{a *}$, Catherine Boussard-Pledel ${ }^{\mathrm{a}}$, Bruno Bureau ${ }^{\mathrm{a}}$ \\ a University of Rennes, ISCR-CNRS-UMR-6226, 35042 Rennes, France \\ *Correspondance: $\underline{\text { bhuvanesh.srinivasan@univ-rennes1.fr }}$
}

\begin{abstract}
GeTe and SnTe based materials are emerging as viable alternatives for toxic PbTe based thermoelectric materials. Here, a systematic study of thermoelectric properties of $\mathrm{Bi}$ and In codoped $\mathrm{GeTe}$, and $\mathrm{Sb}$, In and Ag codoped SnTe alloys processed by Spark Plasma Sintering are presented. We report that codoping of $\mathrm{Bi}$ and In to GeTe, (i) enhances the thermoelectric performance by the synergistic effect of nanostructuring, suppression of carrier density and creation of resonant level, which enables to simultaneously enhance the thermopower and reduce the thermal transport, and (ii) promotes the $R 3 \mathrm{~m}$ $\rightarrow$ Fm-3m structural transition. These cumulative effects help $\mathrm{Ge}_{0.93} \mathrm{Bi}_{0.05} \mathrm{In}_{0.02} \mathrm{Te}$ to maintain the peak figure of merit, $\mathrm{zT} \sim 0.85$ over a wide spectrum of temperature from $550-773 \mathrm{~K}$, making them a serious candidate for device fabrications. We also report that $\mathrm{Sb}$ and $\mathrm{In}$ codoping in SnTe enhances the thermoelectric performance, as $\mathrm{Sn}_{0.845} \mathrm{Sb}_{0.15} \mathrm{In}_{0.005} \mathrm{Te}$ exhibits an improved $\mathrm{zT} \sim 0.8$ at $823 \mathrm{~K}$, when compared to pristine SnTe.
\end{abstract}

Keywords: Thermoelectrics; Codoped GeTe and SnTe; Structural transition; Reduced thermal conductivity; Improved power factor.

\section{Introduction}

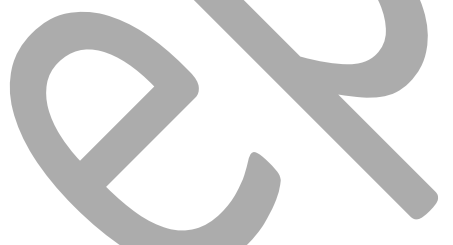

The thermoelectric (TE) material's efficiency is quantified by a dimensionless figure of merit, $z T=S^{2} \sigma T / \kappa$ where $S, \sigma, T$ and $\kappa$ are Seebeck coefficient, electrical conductivity, temperature and total thermal conductivity (sum of electronic and lattice parts, $\kappa_{\mathrm{e}}$ and $\kappa_{\text {latt }}$ ). Amongst the state-of-the-art TE materials, the extensively studied PbTe based materials are limited by their toxicity for any practical applications, despite their high zT [1]. Recently, GeTe and SnTe based materials have emerged as a clear alternative choice, as they have proven to exhibit higher performance $(z T>1)$, if optimally doped with suitable elements [2,3]. 6 mol\% Bi doping in GeTe has shown to exhibit zT $\sim 1.3$ at $723 \mathrm{~K}$ [4], thanks to the collective phonon scattering from nanostructured precipitates and defects, which reduces their $\kappa_{\text {latt. }} 2 \mathrm{~mol} \%$ In doping in GeTe is also shown to exhibit zT 1.3 at $650 \mathrm{~K} \mathrm{[4],} \mathrm{thanks} \mathrm{to} \mathrm{the} \mathrm{resonant} \mathrm{levels} \mathrm{induced} \mathrm{by} \mathrm{In}$ which enhances the thermopower. With an objective to take advantage of these effects, if blended together, we tried codoping of $\mathrm{Bi}$ and In in GeTe, the results of which are presented in this work. Similarly, it has been shown that $15 \mathrm{~mol} \% \mathrm{Sb}$ doping in SnTe has improved the $\mathrm{ZT}$ to 1 at $800 \mathrm{~K} \mathrm{[6],} \mathrm{thanks} \mathrm{to} \mathrm{the}$ phonon scattering via layered intergrowth nanostructures; and the optimal presence of resonant dopant In in SnTe has helped to achieve a peak zT 1.1 at $873 \mathrm{~K}$ [5]; and Ag doping in SnTe has brought in valence band convergence [6]. The improvements achieved with these individual dopants in SnTe, and our foresight to bring in the combined benefits of synergistic band effects and nanostructuring, has inspired us to study the TE of SnTe codoped with $\mathrm{Sb}$, In and Ag. 


\section{Materials \& Methods}

The samples of $\mathrm{Ge}_{1-x-y} \mathrm{Bi}_{x} \mathrm{In}_{y} \mathrm{Te}(\mathrm{x}=0.05,0.07 ; \mathrm{y}=0.02)$ and $\mathrm{Sn}_{1-\mathrm{x}-\mathrm{y}-\mathrm{S}} \mathrm{Sb}_{\mathrm{x}} \operatorname{In}_{\mathrm{y}} \mathrm{Ag}_{\mathrm{z}} \mathrm{Te}(\mathrm{x}=0.15 ; \mathrm{y}=0.0025,0.005$; $z=0,0.0025,0.005)$ were synthesized by vacuum sealed-tube melting process. The obtained ingots were crushed into powders and consolidated by Spark Plasma sintering (SPS) at $773 \mathrm{~K}$ for 5 mins under an axial pressure of $60 \mathrm{MPa}$. Other experimental details were discussed in detail in our previous works [7-9].

\section{Results and Discussion}

The sharp reflections from XRD for GeTe and SnTe based systems indicate the crystalline nature of the phases. The main reflections in Figure $1(\mathrm{a})$ can be indexed to rhombohedral $(R 3 \mathrm{~m})$ GeTe phase. The rhombohedral phase is further confirmed by the presence of double reflections $[(024)$ and $(220)]$ in the range of $2 \theta$ values between $41^{\circ}$ and $44^{\circ}$. Minor proportion of Ge-rich secondary phase is also present. In Figure $1(\mathrm{~b})$, the main reflections can be indexed to cubic $(\mathrm{Fm} 3 \mathrm{~m}) \mathrm{SnTe}$ phase, and the secondary phase closely matches with the pattern of the layered intergrowth Sb-rich compound $\left(\mathrm{Sn}_{m} \mathrm{Sb}_{2 n} \mathrm{Te} \mathrm{e}_{3 n+m}\right)$ [6].

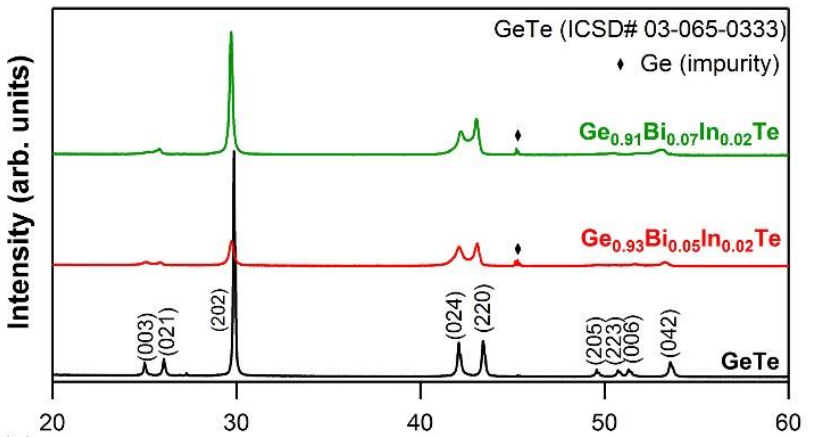

(a)

$2 \theta$ (degrees)

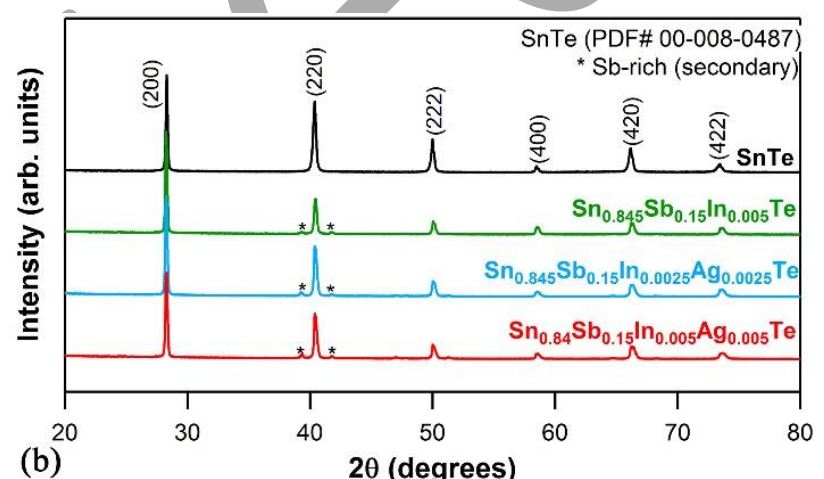

Figure 1. XRD patterns for codoped (a) GeTe based and (b) SnTe based samples.

Codoping of $\mathrm{Bi}$ and In to GeTe drastically decreases the electrical conductivity (Figure 2a), due to the reduction in carrier density, as evident from the Hall measurement results (Table 1). As the Hall voltage is positive in all the samples, holes are the major charge carriers (p-type) in both GeTe and SnTe codoped systems. The reduction in hole concentration during codoping in GeTe, which can be attributed to the aliovalent donor dopant natures of $\mathrm{Bi}^{3+}$ and $\mathrm{In}^{3+}$ at the $\mathrm{Ge}^{2+}$ sub-lattices of GeTe, helps to significantly improve the Seebeck coefficient (Figure $2 b$ ). This improvement in thermopower is anticipated, as In doping in GeTe is known to create resonant state near the Fermi-level $\left(E_{F}\right)$ [4]. The power factor, $P F=\sigma^{2} S$ is presented in Figure $2(\mathrm{c})$. The total thermal conductivity $(\kappa)$ is remarkably reduced by codoping of $\mathrm{Bi}$ and In to GeTe (Figure $2 d$ ). This huge decrease in $\kappa$ arises from the cumulative decrease of both lattice ( $\kappa_{\text {latt }}$ ) and electronic $\left(\kappa_{e}\right)$ contributions, as shown in the Supporting Info (SI, Figure S1). Decreased carrier density is the key cause for suppression of $\kappa_{\mathrm{e}}$, while nanostructuring can be the reason for suppression of lattice contribution, as both Bi doping in GeTe $[2,7]$ and SPS processing are known to create nano-scale defect layers and precipitates, which are effective phonon scatterers. Bi and In codoping in GeTe has helped to concurrently improve the thermopower and suppress the thermal transport. 

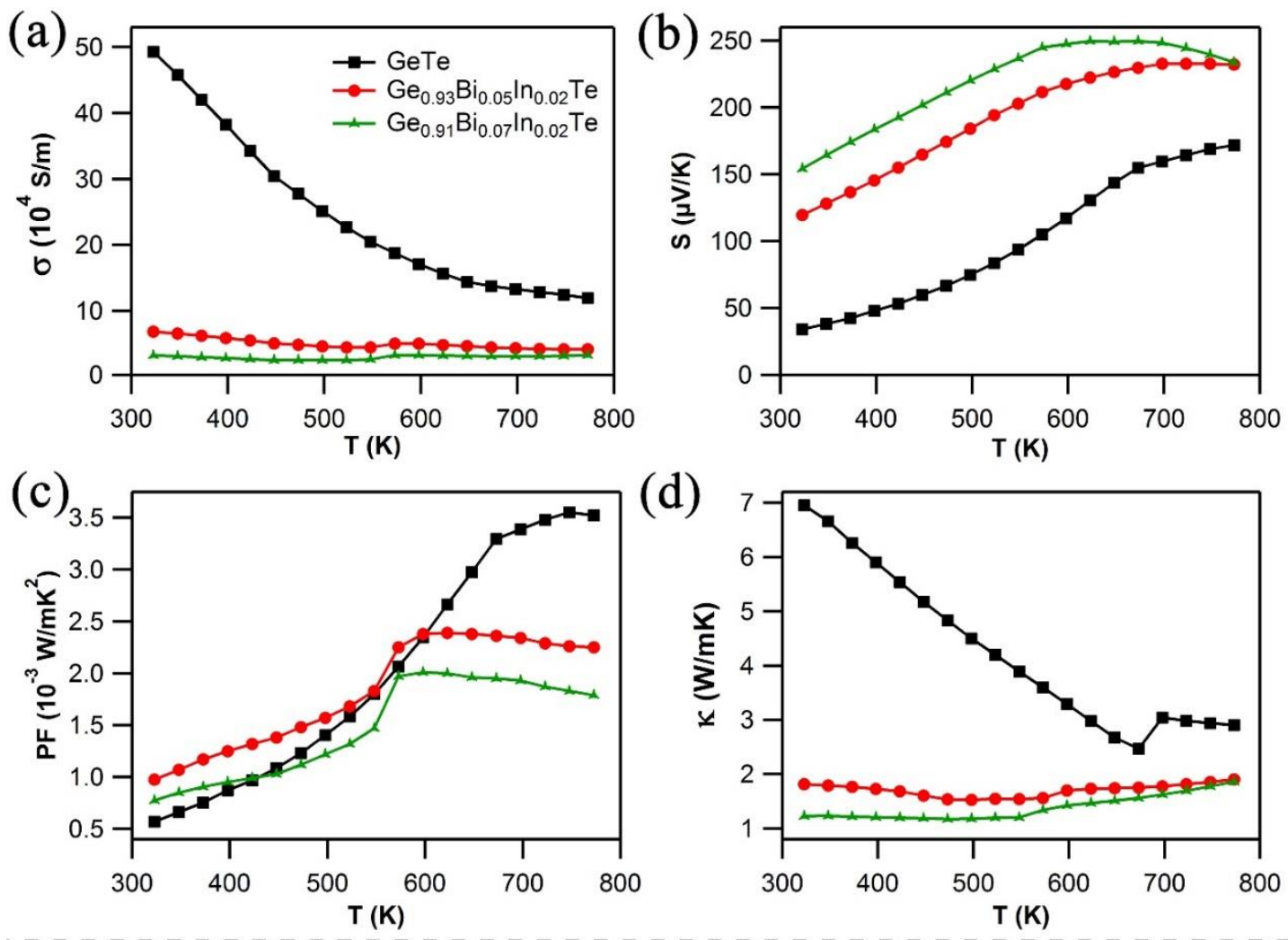

(d)
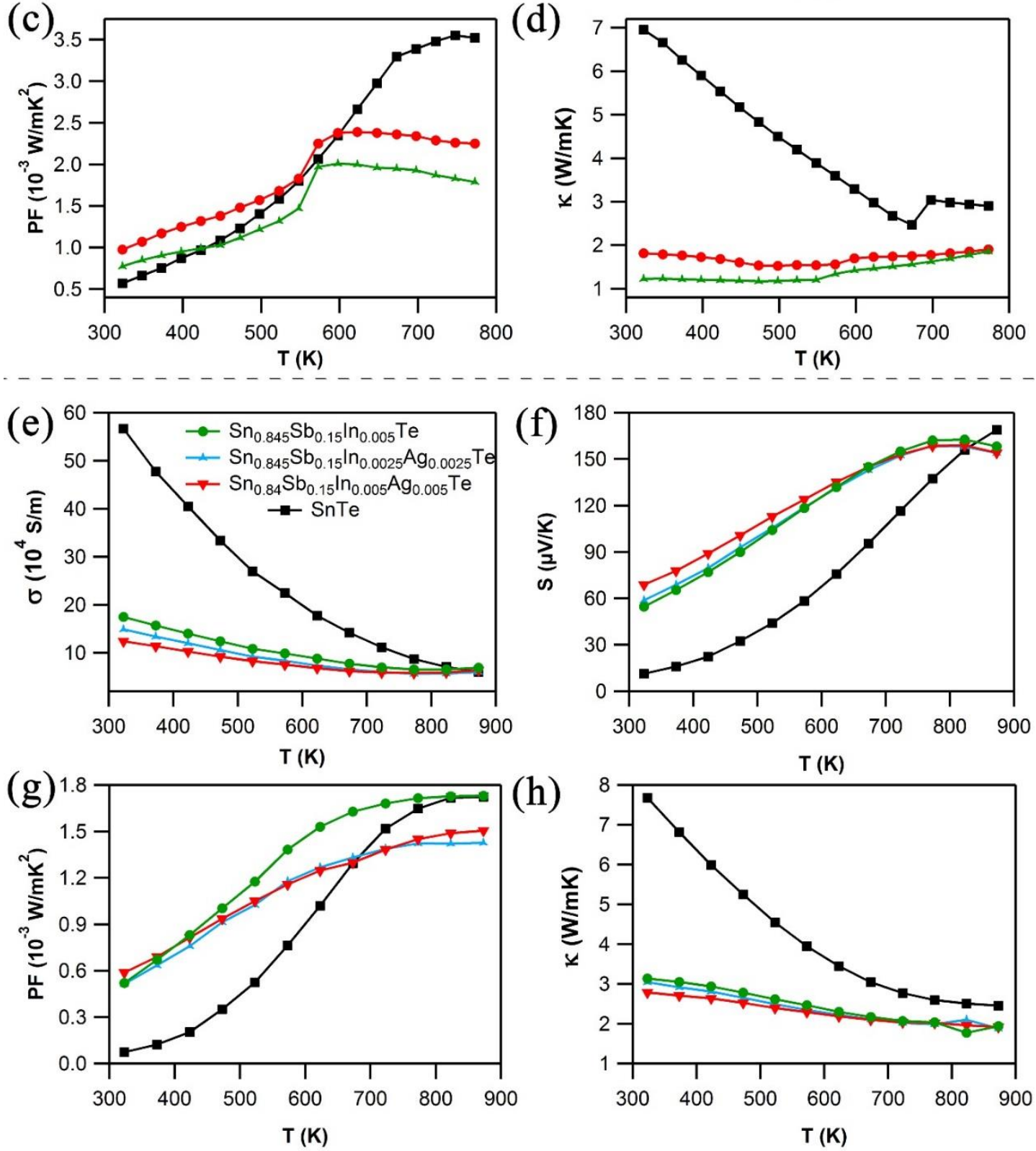

Figure 2. Temperature dependent transport properties for codoped (a-d) GeTe based, and (e-h) SnTe based (e-h) systems. 
Table 1. Hall measurement results (at $300 \mathrm{~K}$ ) of carrier concentration, $n$ and mobility, $\mu$ for GeTe and SnTe based samples.

\begin{tabular}{|ccc|}
\hline Sample & $\begin{array}{c}\text { Carrier Concentration, } \mathbf{n} \\
\left(\mathrm{cm}^{-3}\right)\end{array}$ & $\begin{array}{c}\text { Mobility, } \boldsymbol{\mu} \\
\left(\mathrm{cm}^{2} \mathrm{~V}^{-1} \mathrm{~s}^{-1}\right)\end{array}$ \\
$G e T e$ & $1.02 \times 10^{21}$ & 48.28 \\
$G e_{0.93} B i_{0.05} I n_{0.02} T e$ & $3.78 \times 10^{20}$ & 20.17 \\
$G e_{0.91} B i_{0.07} / n_{0.02} T e$ & $2.21 \times 10^{20}$ & 16.57 \\
$S n T e$ & $3.52 \times 10^{20}$ & 480.5 \\
$S n_{0.845} S b_{0.15} I n_{0.005} T e$ & $4.61 \times 10^{20}$ & 33.72 \\
$S n_{0.845} S b_{0.15} / n_{0.0025} \mathrm{Ag} g_{0.0025} T e$ & $5.14 \times 10^{20}$ & 28.65 \\
$S n_{0.84} S b_{0.15} I n_{0.005} \mathrm{Ag} g_{0.005} T e$ & $5.52 \times 10^{20}$ & 26.98 \\
\hline
\end{tabular}

Codoping of $\mathrm{Sb}, \mathrm{In}$ and $\mathrm{Ag}$ in SnTe has decreased $\sigma$ (Figure 2e) by suppressing the charge carrier mobility (due to impurity scattering caused by In doping $[5,6]$ ), and expectedly increased the Seebeck coefficient (Figure $2 \mathrm{f}$ ) due to resonant states created by In [5]. Just like codoped GeTe, $\kappa$ has also been notably reduced in codoped SnTe (Figure $2 \mathrm{~h}$ ) due to the cumulative decrease of both lattice and electronic contributions (SI, Figure S2). The aggregate effect of nanostructuring, which is expected to arise from $\mathrm{Sb}$ doping to SnTe [6] and SPS processing, has strikingly decreased the thermal transport in codoped SnTe. $\mathrm{Ag}$ was codoped with an objective to bring in valence band convergence in SnTe [6], and as well as to compensate for the loss in $\sigma$ by codoping of $\mathrm{Sb}$ and In in SnTe. But unfortunately, it was not the case, as addition of $\mathrm{Ag}$ to $\mathrm{Sb}$ and In codoped $\mathrm{SnTe}$ has not much beneficial impact on its transport properties. The resonance state, supposedly created by $\mathrm{In}$ in SnTe [5] has helped the In and Sb codoped sample $\left(\mathrm{Sn}_{0.845} \mathrm{Sb}_{0.15} \mathrm{In}_{0.005} \mathrm{Te}\right)$ to exhibit a better thermopower from room temperature to $800 \mathrm{~K}$ and thereby an improved power factor over a wide spectrum of temperature (Figure $2 \mathrm{~g}$ ).

Codoping of In and Bi to GeTe helps to maintain better ZT (Figure 3a) compared to pristine GeTe over a broad temperature domain, due to the simultaneous effects of improved thermopower and reduced thermal transport. Pristine GeTe exhibits peak zT only after $673 \mathrm{~K}$, whereas Bi and In codoped samples exhibit peak $\mathrm{zT}$ at temperatures as low as $550 \mathrm{~K}$. The sample $\mathrm{Ge}_{0.93} \mathrm{Bi}_{0.05} \mathrm{In}_{0.02} \mathrm{Te}$ maintains a consistently high zT of $0.8-0.9$ over a wide range of temperature (550- $773 \mathrm{~K}$ ). From a practical point of view, it is not the peak $z T$, but it is the average $z T$ ( $z T_{\text {ave }}$ ) value that determines the overall efficiency of a TE module. From $550-773 \mathrm{~K}$, the maximum $z \mathrm{~T}_{\text {ave }} \sim 0.85$ is obtained for $\mathrm{Ge}_{0.93} \mathrm{Bi}_{0.05} \mathrm{In}_{0.02} \mathrm{Te}$ sample, which is much higher than pristine GeTe $\left(z \mathrm{~T}_{\text {ave }} \sim 0.6\right)$ and is better than most of the $\mathrm{Sb}$-free GeTe based materials [9]. The other key reason for such improved properties can be due to the fact that the codoping of $\mathrm{Bi}$ and In relaxes the rhombohedral structure of GeTe and pushes the system towards the cubic structure, as the atomic radii of $\mathrm{Bi}(1.43 \AA)$ and In (1.56 $)$ ) are larger comparing Ge (1.25 $)$ ), evident from merging of the rhombohedral double reflections in range of $2 \theta$ values between $41^{\circ}$ and $44^{\circ}$ (Figure $1 \mathrm{a}$ ). In other words, $\mathrm{Bi}$ and In codoping promotes the structural transition $(\mathrm{R3m} \rightarrow \mathrm{Fm}-3 \mathrm{~m})$ faster in GeTe. This is proved by the DSC data (SI, Figure S3), where the structural transition temperature conspicuously reduces from $\sim 700$ $\mathrm{K}$ for pristine GeTe [9] to $\sim 580 \mathrm{~K}$ for $\mathrm{Ge}_{0.93} \mathrm{Bi}_{0.05} \mathrm{In}_{0.02} \mathrm{Te}$. 

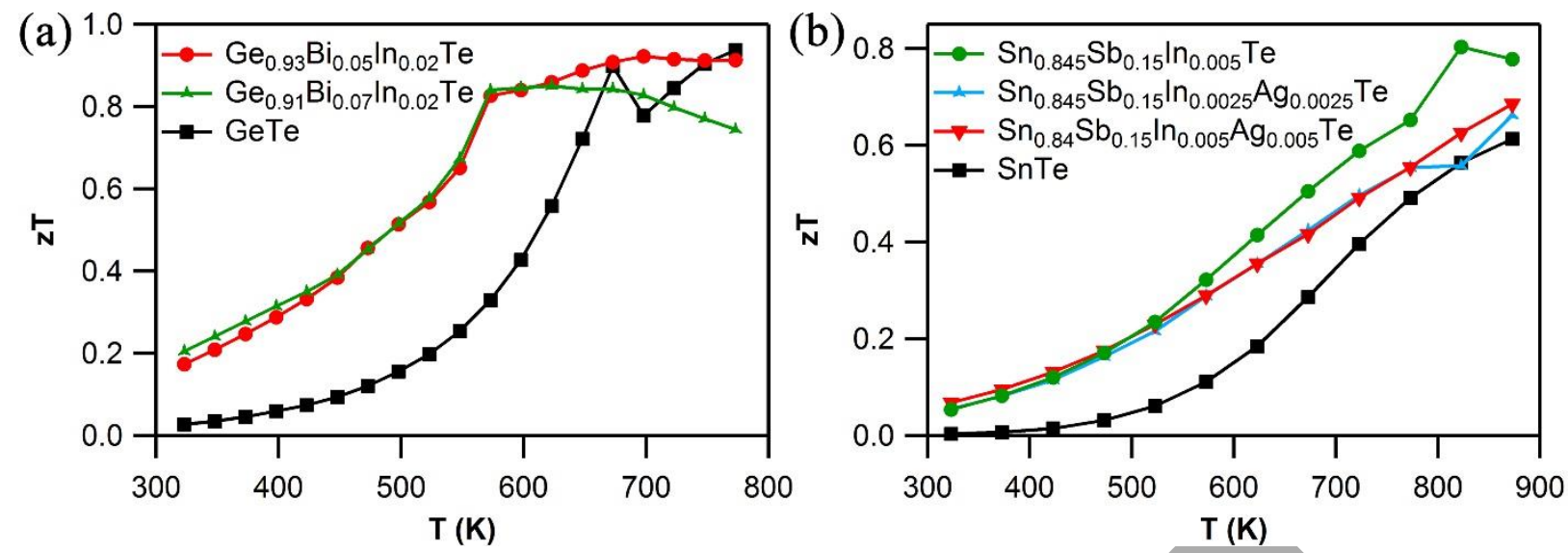

Figure 3. ZT for (a) codoped GeTe, and (b) codoped SnTe systems.

In the $\mathrm{SnTe}$ codoped system, $\mathrm{Sn}_{0.845} \mathrm{Sb}_{0.15} \mathrm{In}_{0.005} \mathrm{Te}$ exhibits a peak $\mathrm{zT} \sim 0.8$ at $823 \mathrm{~K}$, which is higher than undoped SnTe (zT 0.55 at $823 \mathrm{~K}$ ). Moreover, the cumulative effect of improved power factor over a broad spectrum of temperature and reduced thermal conductivity helps the Sb and In codoped SnTe to exhibit a higher $\mathrm{zT}_{\text {ave }}$ compared to pristine $\mathrm{SnTe}$.

Though the TE properties for the codoped compositions when compared to their base materials are good, the doping elements which have distinctive roles and cause different band effects can at times heavily distort the density of states (DOS), if the codoping level is not balanced or optimized. Such heavy distortion of DOS can adversely affect $\sigma$ (as in Figure 2a, 2e). This explains the reason for the codoped compositions (double or triple doping) that is presented in this work for exhibiting a relatively lower $\mathrm{zT}$ when compared to the singly doped compositions.

\section{Conclusion}

Codoping of $\mathrm{Bi}$ and In to GeTe, expected to foster resonant state near Fermi-level (induced by In) and nanostructured precipitation (by Bi and SPS process), has helped to (i) suppress the carrier density, (ii) enhance the thermopower, (iii) reduce the thermal transport, and (iv) favored the rhombohedral to cubic structural transition, thus ultimately making them as potential candidates for mid-temperature device fabrications, as they maintain a constant high zT $\sim 0.85$ over a wide spectrum of temperature $(550-773$ $\mathrm{K})$. Similarly, codoping of Sb and In to SnTe, expected to bring in In-induced resonance state and nanostructuring (by Sb and SPS process), has helped to improve the $\mathrm{zT}$ to $\sim 0.8$ at $823 \mathrm{~K}$ by the concurrent effect of enhanced power factor and suppressed thermal conductivity.

\section{Acknowledgement}

European Commission's H2020-MSCA grant (GA.642557, CoACH-ETN) and Prof. Mike Reece (QMULondon) are acknowledged.

\section{References}


[1] B. Srinivasan, F. Gucci, C. Boussard-Pledel, F. Cheviré, M.J. Reece, S. Tricot, L. Calvez, B. Bureau, J. Alloys Compd. 729 (2017) 198-202.

[2] S. Perumal, S. Roychowdhury, K. Biswas, Inorg. Chem. Front. 3 (2016) 125-132.

[3] A. Banik, B. Vishal, S. Perumal, R. Datta, K. Biswas, Energy Environ. Sci. 9 (2016) 2011-2019.

[4] L. Wu, X. Li, S. Wang, T. Zhang, J. Yang, W. Zhang, L. Chen, J. Yang, NPG Asia Mater. 9 (2017) e343.

[5] Q. Zhang, B. Liao, Y. Lan, K. Lukas, W. Liu, K. Esfarjani, C. Opeil, D. Broido, G. Chen, Z. Ren, Proc. Natl. Acad. Sci. U. S. A. 110 (2013) 13261-13266.

[6] A. Banik, U.S. Shenoy, S. Saha, U.V. Waghmare, K. Biswas, J. Am. Chem. Soc. 138 (2016) 1306813075.

[7] B. Srinivasan, C. Boussard-Pledel, V. Dorcet, M. Samanta, K. Biswas, R. Lefèvre, F. Gascoin, F. Cheviré, S. Tricot, M. Reece, B. Bureau, Materials. 10 (2017) 328.

[8] B. Srinivasan, S. Cui, C. Prestipino, A. Gellé, C. Boussard-Pledel, S. Ababou-Girard, A. Trapananti, B. Bureau, S. Di Matteo, J. Phys. Chem. C. 121 (2017) 14045-14050.

[9] B. Srinivasan, R. Gautier, F. Gucci, B. Fontaine, J.-F. Halet, F. Cheviré, C. Boussard-Pledel, M.J. Reece, B. Bureau, J. Phys. Chem. C. 122 (2018) 227-235.

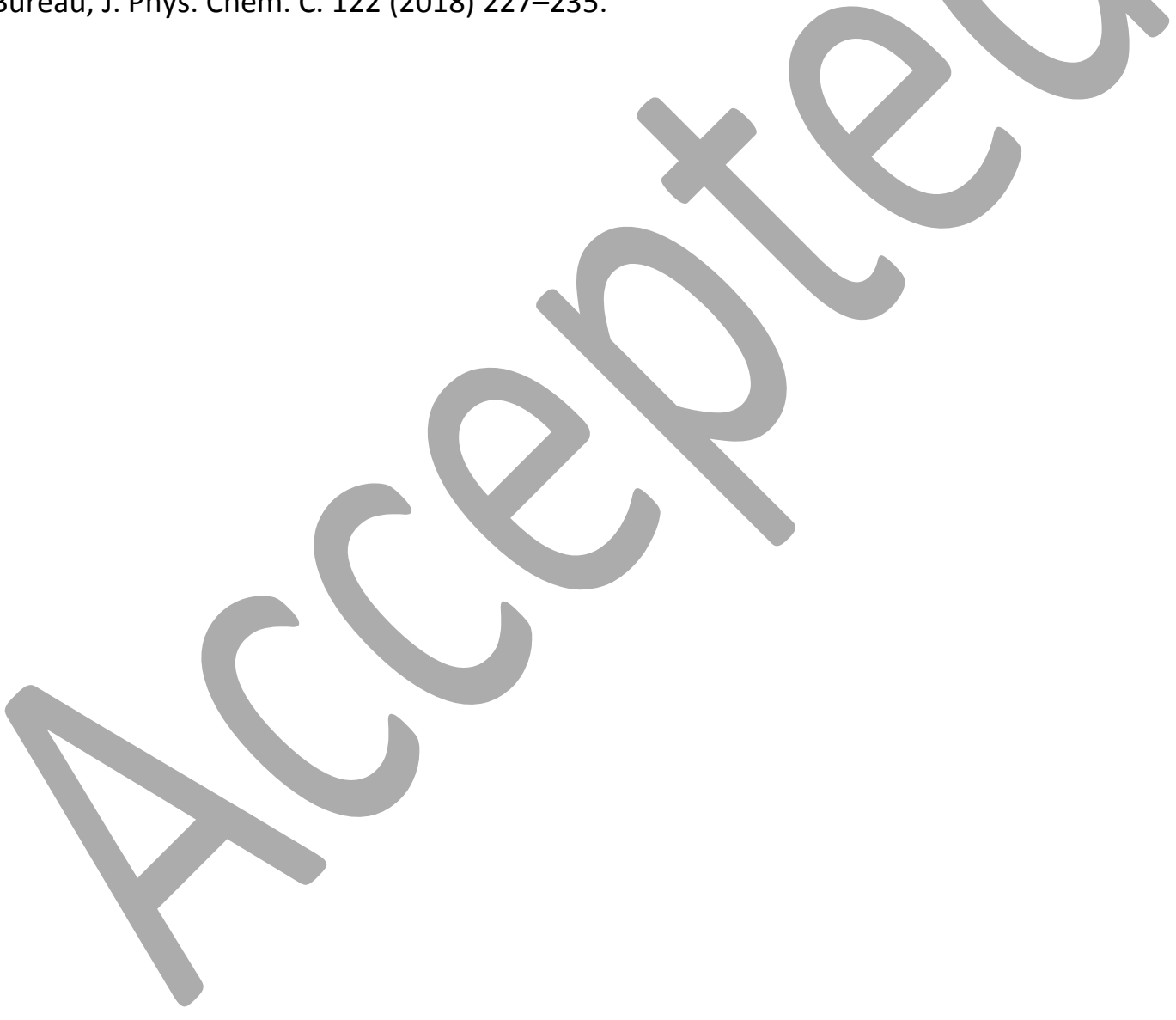

